\title{
Bupivacaine-induced Apoptosis in the Primary Cultured Cardiomyocytes via p38 MAPKs
}

\author{
*Department of Dental Anesthesiology, Seoul National University College of Dentistry, Seoul; \\ ${ }^{+}$Department of Anesthesiology and Pain Medicine, Chungbuk National University College of Medicine, Cheongju; \\ * Department of Anesthesiology and Pain Medicine, \\ Seoul National University College of Medicine, Seoul, Korea \\ Hyun Jeong Kim, M.D.*, Se Ra Sung, M.S.*, Kwang Suk Seo, M.D.*, \\ Seung Woon Lim, M.D. ${ }^{\dagger}$, and Tae Gyoon Yoon, M.D. ${ }^{\ddagger}$
}

Background: It is known that bupivacaine induce cell death in several immortalized cells. However, there is no report concerning bupivacaine-induced cell death in the primary cultured cardiomyocytes. We compared the direct cytotoxicity of local anesthetics in cardiomyocytes. Furthermore, the mechanisms of cell death were evaluated.

Methods: The myocardial cells of rat pups were cultured 3 days after seeding. The methyltetrazolium (MTT) assay was employed to quantify differences in cellular viability. To confirm apoptosis, Hoechst-propidium iodide staining, DNA fragmentation by electrophoresis and western blot analysis were performed. And to examine the mechanisms of cell death, intracellular calcium and expression levels of mitogen-activated protein kinases (MAPKs) family members were evaluated.

Results: Among the local anesthetics under $1 \mathrm{mM}$ concentration for $18 \mathrm{~h}$, only bupivacaine significantly decreased the MTT activity $(\mathrm{P}<0.001)$. Bupivacaine induced cell death in a dose-responsive and time dependent manner. Cell death showed apoptotic characteristics, such as DNA fragmentation, chromatin condensation, decrease of precursor caspase-3 protein level, increased cleaved PARP, and cytochrome $\mathrm{C}$ release into the cytoplasm. Bupivacaine phosphorylated three major MAPKs, i.e. extracellular signalregulated kinases (ERKs), p38 kinase and c-Jun N-terminal kinases (JNKs) stress-activated protein kinases. Administration of ERK inhibitor increase cell death, whereas inhibitors of p38 kinase and JNK decreased cell death $(\mathrm{P}<0.05)$. In addition, the intracellular calcium level was approximately 4 times higher after the bupivacaine treatment $(\mathrm{P}<0.001)$, which was inhibited by calcium chelators $(\mathrm{P}<0.001)$. Calcium chelators inhibited expression of MAPKs.

Conclusions: In bupivacaine-induced apoptosis in cardiomyocytes, intracellular calcium increase and MAPKs family plays important roles. (Korean J Anesthesiol 2006; 50: S 48 56)

Key Words: apoptosis, bupivacaine, calcium, cardiomyocyte, levobupivacaine, mitogen-activated protein kinases.

\section{INTRODUCTION}

Many local anesthetics are associated with fatal cardiotoxicity related to potent depressant effect on electrical conduction in the heart and reentrant types of severe arrhythmia in patients. $^{1-4)}$ Recently, some local anesthetics-induced direct cytotoxicity related to the initiation or execution of apoptosis has been

\section{Received : February 7, 2006}

Corresponding to : Tae Gyoon Yoon, Department of Anesthesiology and Pain Medicine, Seoul National University College of Medicine, 28 Yeongeon-dong, Jongno-gu, Seoul 110-744, Korea. Tel: 82-2-20723295, Fax: 82-2-745-5587, E-mail: ytg001@dreamwiz.com

This article is a doctoral dissertation.

The levobupivacaine used in this study was thankfully donated by the Astra-Geneca. reported. $^{5,6)}$ However, regarding to bupivacaine-induced apoptosis, little is known except in the promyelocytic leukemia cells, ${ }^{7}$ human proximal tubular (HK-2) cells, ${ }^{8)}$ and in the skeletal muscle tissue. ${ }^{9)}$ Furthermore, there is no report in the cardiomyocytes, which may be important related to bupivacaine toxicity.

Basically, there are two principal forms of cell death; necrosis and apoptosis. ${ }^{10)}$ According to the classical view, necrosis is the major mechanism of cardiomyocyte death in cardiac diseases. However, cardiomyocyte apoptosis occurs in diverse pathologic conditions, such as myocardial infarction, congestive heart failure, hypertension, even arrhythmogenic right ventricular dysplasia (ARVD). ${ }^{11,12)}$

Apoptosis is an active gene-directed cell death process, which plays a key role in myocardial demage. ${ }^{13,14)}$ For example, cardiomyocytes cell death occurs in condition of myocardial in- 
farction, cell death after prolonged periods of ischemia is ascribed to necrosis, reperfusion to apoptosis. Generally, myocardial ischemia/reperfusion activates the two stress-responsive mitogen-activated protein kinase (MAPK) subfamilies, namely, cJun N-terminal kinases (JNK) and p38 mitogen-activated protein kinases (p38 MAPKs), resulting in apoptosis. ${ }^{15)}$

It was also known that local anesthetics such as lidocaine cause intracellular calcium $\left(\left[\mathrm{Ca}^{2+}\right]_{i}\right)$ increase via $\mathrm{Ca}^{2+}$ influx through plasma membrane ${ }^{5)}$ and increased intracellular calcium regulates several key steps in the apoptotic signaling pathway in cardiomyocytes, ${ }^{16-18)}$ skeletal muscles ${ }^{19)}$ and immortalized cell. ${ }^{20)}$

Taken together, the aims of this study were threefold: (1) to determine whether local anesthetics have cytotoxic effects on the primary cultured cardiomyocytes; (2) to determine whether bupivacaine-induced cell death is apoptosis, (3) to determine MAPKs and calcium have some role in bupivacaine-induced cell death.

\section{MATERIALS AND METHODS}

The experimental protocol was approved by Ethics Committee for Animal Experimentation and was performed according to the Guidelines for Animal Experimentation of Seoul National University.

\section{Primary cardiomyocytes culture}

All the procedure and protocol was approved by the Animal Care and Use Committee of Seoul National University College of Dentistry.

Neonatal rat hearts were obtained from 1-2 day (s) old Sprague-Dawley rats that were anesthetized with putting them in the middle of ice. The hearts from the rats were dissected, minced, and placed in an ADS buffer $(116 \mathrm{mM} \mathrm{NaCl}, 20 \mathrm{mM}$ HEPES, $9.4 \mathrm{mM} \mathrm{NaH} \mathrm{PO}_{4}, 5.5 \mathrm{mM}$ glucose, $5.4 \mathrm{mM} \mathrm{KCl}$, $0.4 \mathrm{mM} \mathrm{MgSO}$, $\mathrm{pH}$ 7.4). The heart was cut into 1 to $2 \mathrm{~mm}$ pieces and digested with $0.06 \%$ pancreatin (Sigma Chemical $\mathrm{Co}$, St. Louis, MO) and $0.03 \%$ type II collagenase (Sigma) in an ADS buffer for $20 \mathrm{~min}$ at $37^{\circ} \mathrm{C}$ in a hybridization oven. The dissociated cells were collected by centrifugation and were resuspended in DMEM with 10\% FBS, 100 units/ml penicillin (Gibco BRL Life Technologies, Grand Island, NY). The dissociated cells were plated in collagen-coated $100 \mathrm{~mm}$ culture dishes for $40 \mathrm{~min}$ at $37^{\circ} \mathrm{C}$ in a $\mathrm{CO}_{2}$ incubator. This procedure results in predominantly fibroblasts attaching to the dishes, while most cardiomyocytes remain unattached. The population of cells enriched in the cardiomyocytes by differential plating were collected and counted. The cells were seeded at a density of $7.5 \times 10^{4}$ cells per collagen-coated 96 well plates or 3.5 $\times 10^{6}$ cells per collagen-coated $60 \mathrm{~mm}$ dishes. The cells were cultured in Dubeccos Modified Eagles medium (DMEM) with $10 \%$ FBS, 100 units $/ \mathrm{ml}$ penicillin and $100 \mathrm{gg} / \mathrm{ml}$ streptomycin. The cells were replaced with fresh medium on the second day of plating. At 3 or 4 days after plating, the cells were treated with lidocaine, ropivacaine, and bupivacaine.

\section{The methyl tetrazolium (MTT) assay}

The cells were seeded into 96-well plates at a concentration of $7.5 \times 10^{4}$ cells/well. In order to observe the cytotoxic effects of local anesthetics, the neonatal cardiomyocytes were exposed to lidocaine, ropivacaine, levobupivcaine and bupivacaine, from 1$\lrcorner \mathrm{M}$ to 1,000$\lrcorner \mathrm{M}$ for 18 hours with serum free media. The medium was removed after incubation. For the MTT assay, DMEM containing 10\% FBS and $0.5 \mathrm{mg} / \mathrm{ml}$ MTT (Methylthiazoletetrazolium: Thyazolyl Blue: Tetrazolium bromide) was added to ea0ch of the 96 well plates for $2 \mathrm{~h}$ at $37^{\circ} \mathrm{C}$ in a $\mathrm{CO}_{2}$ incubator. After $2 \mathrm{~h}$, the medium was removed and 1001 of dimethyl sulfoxide (DMSO) was added. The absorbance at $570 \mathrm{~nm}$ and $630 \mathrm{~nm}$ was recorded using a spectrophotometer (Bio-TEK Instruments Inc., Winooski, VT).

\section{DNA fragmentation on agarose gels}

The characteristic formation of the oligonucleosome-sized fragments of multiples of about 200 base pairs (bp) producing the typical DNA ladders on agarose gels is the biochemical hallmark of apoptosis. After the treatments, the cells were harvested and lysed in a lysis buffer $(100 \mathrm{mM} \mathrm{NaCl}, 10 \mathrm{mM}$ Tris-HCl [pH 8.0], $25 \mathrm{mM}$ EDTA, and 0.5\% sodium dodecylsufate (SDS)), which was followed by incubation with 100 $\mathrm{gg}$ proteinase $\mathrm{K}$ (Sigma) for $4 \mathrm{~h}$ at $37^{\circ} \mathrm{C}$. The protein was removed through the addition of phenol and chloroform and was centrifuged at $13,000 \mathrm{~g}$ for $15 \mathrm{~min}$. The DNA was precipitated from the supernatant with the two volumes of absolute alcohol and centrifuged at 13,000 $\mathrm{g}$ for $15 \mathrm{~min}$. The pellet was washed twice with $70 \%$ ethanol. The DNA was dissolved in TrisEDTA buffer containing $0.5 \mathrm{U}$ of DNase-free RNase A. The DNA concentration was measured by spectrophotometry (Perkin Elmer Instruments, Shelton, CT) and 10 g of each DNA was electrophoretically fractionated in a $1.8 \%$ agarose gel with ethidium bromide.

2 acetoxymethyl ester (Fura-2 AM, Molecular probes, Eugene, OR). Briefly, the cells attached to the glass coverslips (di- 
ameter, $12 \mathrm{~mm}$ ) were washed twice in Krebs-Ringer-HEPES

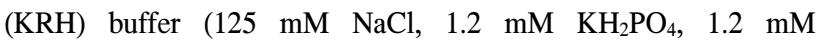
$\mathrm{MgCl}_{2}, 6 \mathrm{mM}$ glucose, $1 \mathrm{mM} \mathrm{CaCl} 2$ and $25 \mathrm{mM}$ HEPES, $\mathrm{pH}$ 7.4) and then incubated in KRH buffer containing 4 M Fura$2 \mathrm{AM}$ for $30 \mathrm{~min}$ at $37^{\circ} \mathrm{C}$ in a $\mathrm{CO}_{2}$ incubator. The loaded cells were then washed twice with $\mathrm{KRH}$ buffer. A coverslip with the cultured cardiomyocytes was placed on the chamber and a vacuum seal was formed between the ring and coverslip with vacuum grease. The coverslip with the cultured cells was filled with 1001 of the KRH buffer. The changes in the fluorescence intensity of the Fura-2 at excitation wavelengths of $340 \mathrm{~nm}$ and $380 \mathrm{~nm}$ and emission wavelength $510 \mathrm{~nm}$ were determined using by microspectrofluorometry technique (Photon Technology International, UK). The ratio of the fluorescence emitted at $510 \mathrm{~nm}$ in response to the alternate excitation at $340 \mathrm{~nm}$ and $380 \mathrm{~nm}(340 \mathrm{~nm} / 380 \mathrm{~nm}$ ratio $)$ was the index of $\left[\mathrm{Ca}^{2+}\right]_{i}$.

\section{Reactive oxygen species (ROS) measurement}

Level of ROS in cells was measured using the fluorescent probe 2, 7-dichlorodihydrofluorescein diacetate (Molecular probes D-399, Oregon, USA). The procedure is based on the oxidation of 2, 7-dichlorodihydrofluorescein $\left(\mathrm{H}_{2} \mathrm{DCF}\right)$ in the presence of ROS to the highly fluorescent, dichlorodihydrofluorescein (DCF), reflecting the rate of oxidation of the dye precursor, i.e. velocity constant. After removal of the media, cardiomyocyte cultures were loaded for $30 \mathrm{~min}$ with $50 \mathrm{M} 2$, 7-dichlorodihydrofluorescein diacetate $\left(\mathrm{H}_{2} \mathrm{DCFA}\right)$ in a $37^{\circ} \mathrm{C}, 5 \%$ $\mathrm{CO}_{2}$ incubator and washed in Hanks Balanced Salt Solution (HBSS). And the fluorescence intensity was monitored using multiwell fluorescence plate reader. For all experiments, fluorescence was measured at $37^{\circ} \mathrm{C}$ with a FLx 800 multiwell fluorescence plate reader, set at $490 \mathrm{~nm}$ excitation and $526 \mathrm{~nm}$ emission wave length (Perkin Elmer LS-55). The percent change in fluorescence for each well was determined from [ $[$ Ft60$F t 0) / F t 0 \times 100]$, where Ft60 refers to fluorescence at approximately $60 \mathrm{~min}$ and $F t 0$ refers to fluorescence at time $0 \mathrm{~min}$.

Treatment of MAPKs inhibitors and intracellular and extracellular calcium inhibitors

After confirming non-toxic effect of chelators with the basal MTT assay of at the doses of 10M of BAPTA-AM (Sigma Chemical Co, St. Louis, MO) and $0.5 \mathrm{mM}$ EGTA (Sigma), these inhibitors were pre-treated with the primary cardiomyocytes. After the treatment of chelators, the primary cardiomyo- cytes were treated with 700دM of bupivacaine for $18 \mathrm{~h}$.

\section{Statistics}

The data from the MTT assay is expressed as a mean \pm $\mathrm{SD}$ in terms of the percentage. ANOVA followed by a Tukey's post hoc test and a Dunnett's multiple comparisons test were used to compare the differences in the MTT assay between the concentrations of each local anesthetic. A p value $<0.05$ was considered significant. The dose-response data of bupivacaine were fitted to a logistic equation, yielding 50\% effective dose $\left(\mathrm{ED}_{50}\right)$, slopes, and estimates of its $95 \%$ confidence interval (CI). The increase of intra-cellular calcium of the bupivacaine-induced apoptotic cells was compared to the control with Student's t-test. All statistical analyses were performed using SPSS 10.0 (SPSS Inc, Chicago, IL).

\section{RESULTS}

Bupivacaine induces cell death in cardiomyocytes and apototic features were evident

Whether lidocaine, ropivacaine, levobupivacaine and bupivacaine induced cell death were examined at various concentrations from 1 to $1,000 \mathrm{M}$ for $18 \mathrm{~h}$. Among treated local anesthetics, only bupivacaine showed significant cell death at a concentration of $1 \mathrm{mM}$ compared to the control and other local anesthetics $(\mathrm{P}<0.001$, Fig. 1).

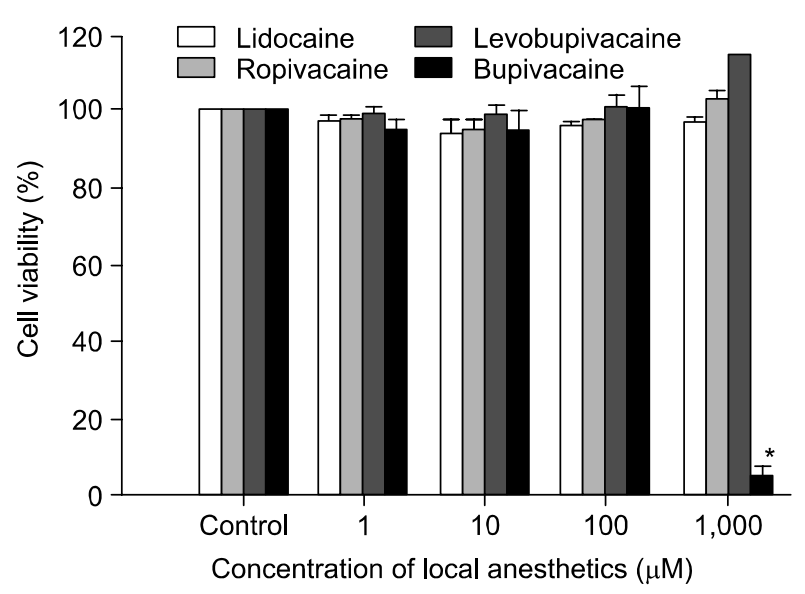

Fig. 1. Cell viability was compared among lidocaine, ropivacaine, levobupivacaine and bupivacaine in the primary cultured cardiomyocytes. The amount of cell viability was measured by the MTT assay. Among treated local anesthetics for $18 \mathrm{hr}$, only bupivacaine induced the cell death at a concentration of $1 \mathrm{mM}$. *: P $<0.001$ as compared with the control. 
A

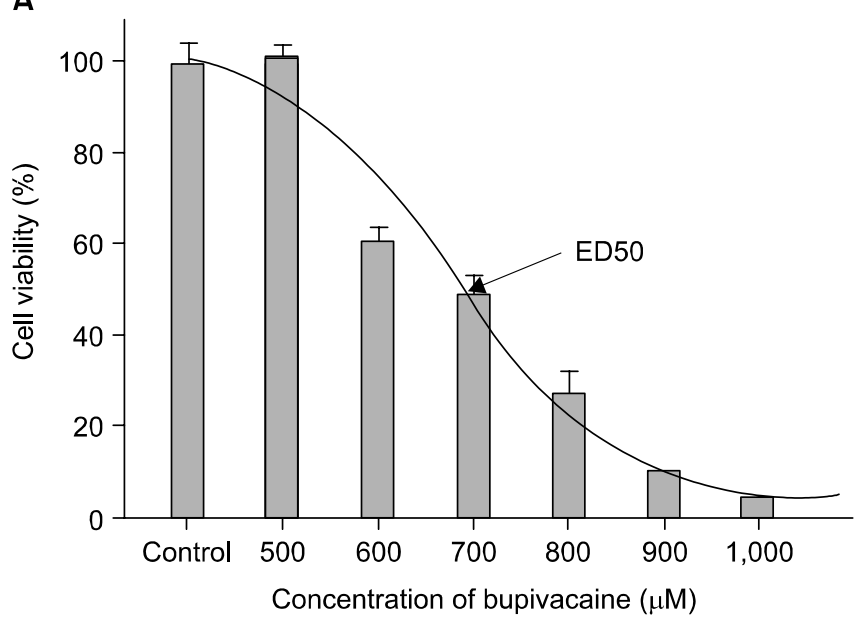

B

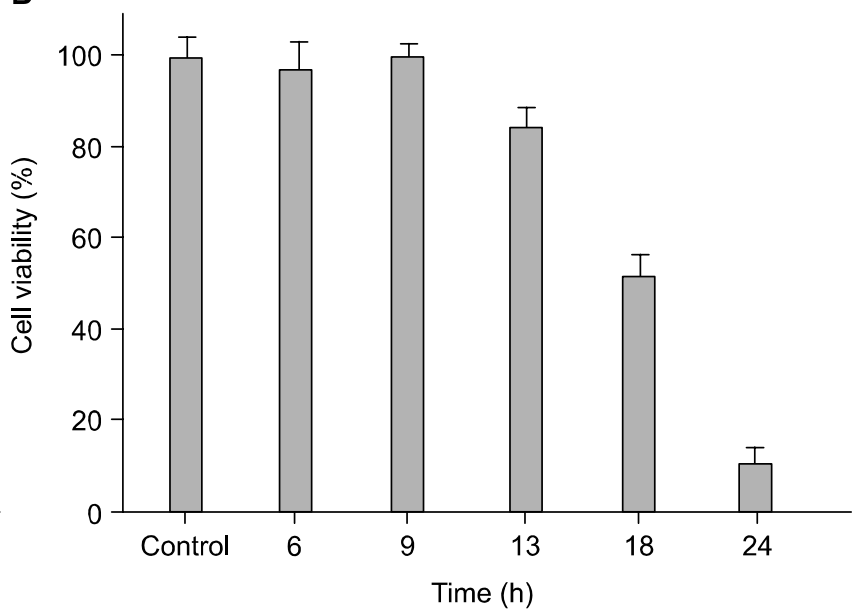

Fig. 2. Bupivacaine-induced cell death. It occurred in a dose (A) and time dependent manner (B) measured by the MTT assay. The results are represented as a mean \pm SD of the values obtained from five independent experiments and are expressed as a percentage of the corresponding mean control value. (A) Dose-responsiveness was observed during the bupivacaine treatment for $18 \mathrm{hr}$. (B) The time- course of the cell death was after the treatment of $700 \mathrm{M}$ bupivacaine. The $50 \%$ effective dose (ED50) was calculated statistically as $696 \mathrm{M}$ (confidence interval is $\mathrm{P}<0.05)$.
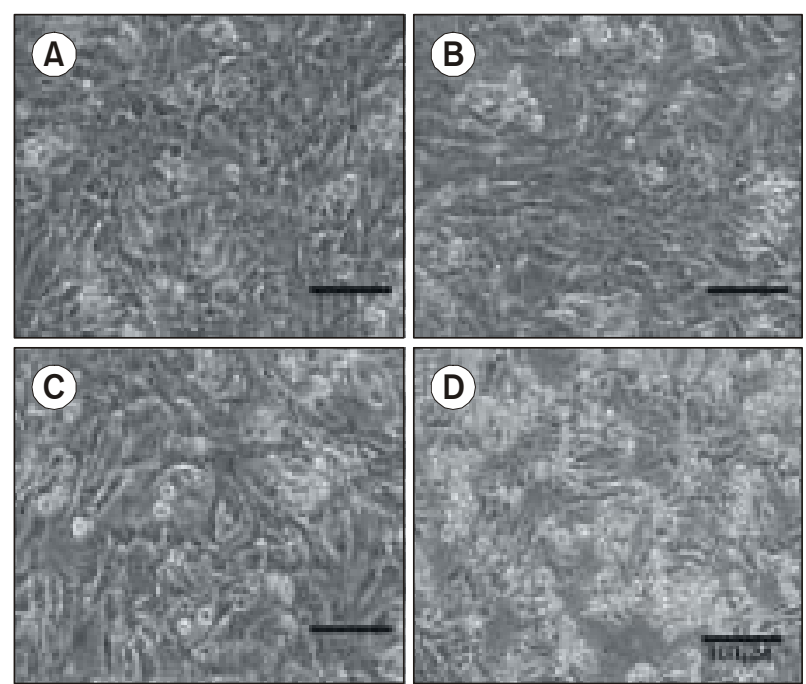

Fig. 3. The microscopic morphological changes after bupivacaine treatment. The cardiomyocytes cell morphology was examined using phase-contrast microscopy in the absence (A) and presence of 700 $\mu \mathrm{M}$ bupivacaine for 6 (B), 9 (C), and $18 \mathrm{hr}(\mathrm{D})$, respectively. The untreated healthy cardiomyocytes showed active beating (A). Up to 6 $\mathrm{hr}$, the $700 \mathrm{M}$ bupivacaine treated cardiomyocytes did not show any abnormal findings except losing their typical beating activity (B). However, after $9 \mathrm{hr}$, they appeared to have condensed nuclei and transformed to an elongated cell shape in some cardiomyocytes (C). After $18 \mathrm{hr}$ almost all the cardiomyocytes lost their cellular integrity or had detached from the bottom of the culture plate (D).
The bupivacaine-induced cell death showed in a dose and time dependent manner (Fig. 2). About $50 \%$ of cells were dead after treatment with $700 \mathrm{M}$ bupivacaine for $18 \mathrm{~h}$. Cardiomyocyte death occurred abruptly over 550 $\mu \mathrm{M}$ after the bupivacaine treatment for $18 \mathrm{~h}$ (Fig. 2A) and $13 \mathrm{~h}$ after the exposure to 700 M bupivacaine (Fig. 2B). The statistically calculated ED50 was $696 \mu \mathrm{M}$ (95\% C.I. $678-714\lrcorner \mathrm{M}$, Fig. 2A).

The microscopic findings were as follows. The untreated healthy cardiomyocytes showed active beating (Fig. 3A). Up to $6 \mathrm{~h}$, cardiomyocytes treated with 700دM of bupivacaine did not show any abnormal findings except losing their typical beating activity (Fig. 3B). However, after 9 h, they appeared to have condensed nuclei and transformed to an elongated cell shape in some cardiomyocytes (Fig. 3C). After $18 \mathrm{~h}$ almost all the cardiomyocytes lost their cellular integrity or had detached from the bottom of the culture plate (Fig. 3D). These observations were generally consistent with the assessment of cell death using Hoechst-PI staining (Fig. 4B, C) and the data from the MTT assay (Fig. 1).

Nuclei were examined by staining with Hoechest-PI staining (Fig. 4A). After treatment of 550 (Fig. 4B) and $700 \mu \mathrm{M} \mathrm{bu-}$ pivacaine (Fig. 4C) for $18 \mathrm{~h}$, the arrows indicate the nuclei of dead cells with condensation, and fragmented nuclei compared to control (Fig. 4A).

In the electrophoresis, DNA fragmentation was shown $6 \mathrm{~h}$ 

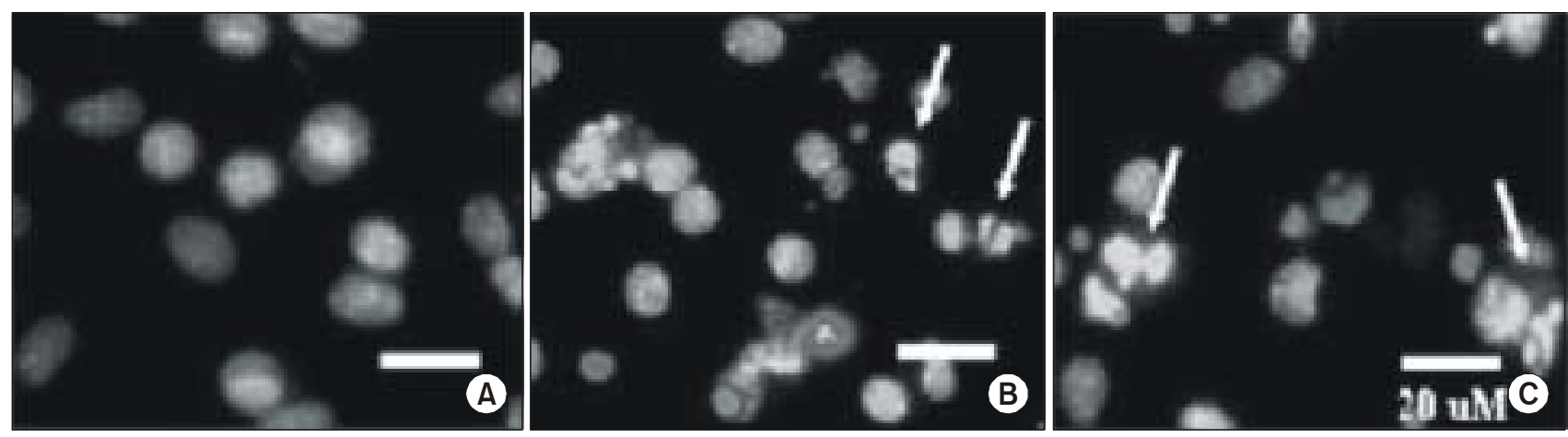

Fig. 4. Hoechst-PI nuclear staining after bupivacaine treatment. Hoechst-PI nuclear staining showed major nuclear alterations in the cardiomyocytes after the 700 M bupivacaine treatment for 9 (B), and $18 \mathrm{hr}(\mathrm{C})$ as compared to the control (A). Arrows indicate bupivacaine- induced condensed, coalesced, and segmented nuclei with a brighter blue fluorescence. The proportion of dead cardiomyocytes was quantified by PI staining (red color). In (C), the population of the cardiomyocytes is small because of cellular detachment, which were removed during the staining procedures. The apoptotic phenomena, definite nuclear condensation and fragmentation, were observed.

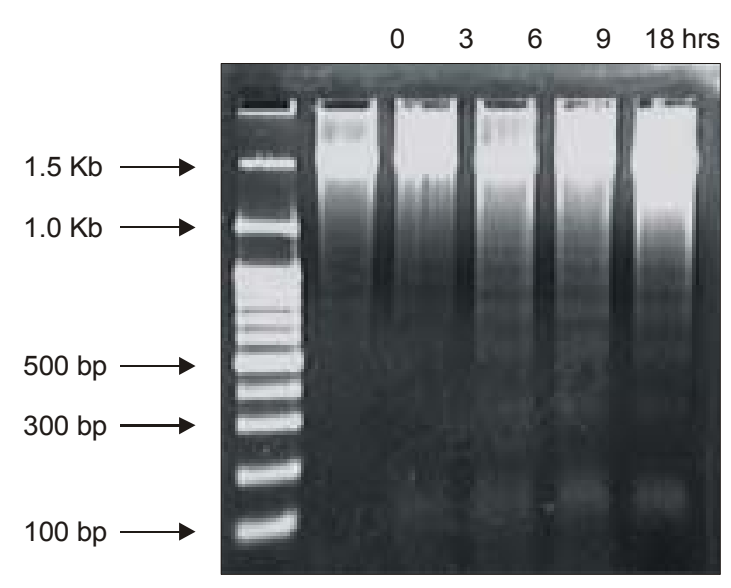

Fig. 5. Enhancement of DNA laddering by bupivacaine. The primary cultured cardiomyocytes were treated with after $550 \mu \mathrm{M}$ bupivacaine. The formation of DNA ladder was examined in $1.8 \%$ agarose gel. The typical apoptotic DNA ladders were shown with 550 M of bupivacaine for 9 and $18 \mathrm{hr}$ treatment. Similar results were obtained from five additional separate experiments.

after treatment with $550 \mathrm{M}$ bupivacaine, and then after $18 \mathrm{~h}$, DNA laddering was prominent (Fig. 5). These nuclear findings were compatible with apoptotic cell death.

Western blot analysis also showed PARP cleavage and procaspase 3 decreases after $550 \mathrm{M}$ of bupivacaine over time. We could also observe cytochrome c release from mitochondria into cytoplasm at $3 \mathrm{~h}$ after bupivacaine treatment (Fig. 6). Taken together, bupivacaine may induce apoptosis in the primary cultured cardiomyocytes.

These finding suggest apoptotic processes were involved in bupivacaine induced apoptosis of cardiomyocytes.

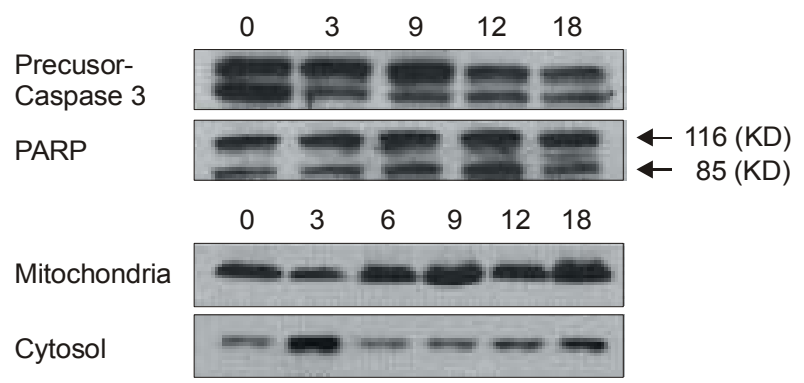

Fig. 6. Bupivacaine-induced the mitochondrial caspase dependent apoptosis western blot analyses of precusor caspase 3, PARP and cytosoloc cytochrome $\mathrm{C}$ expression.

\section{MAPKs involved in bupivacaine-induced apoptosis in cardiomyocytes}

To elucidate the molecular mechanism of bupivacaine-induced apoptosis of cardiomyocytes, whether bupivacaine activates MAPKs in cardiomyocytes were examined. When cardiomyocytes were exposed to 700 $\mathrm{M}$ bupivacaine for $0,3,6,12$, and $18 \mathrm{~h}, \mathrm{p}-\mathrm{p} 38$ and p-JNK expression levels were peaked at $3 \mathrm{~h}$ and maintained thereafter (Fig. 7). Unlike phosphorylated MAPKs (p-ERKs, p-p38 and p-JNK), the activity of ERKs, p38 and JNK showed no change of expression levels after bupivacaine treatment. These findings suggest that the basal level of ERKs, p38 and JNK were maintained in spite of bupivacaine-induced apoptosis (Fig. 7A).

Treatment with PD98059, which is the ERKs inhibitor, significantly increased cell death $(\mathrm{P}<0.05$, Fig. $7 \mathrm{~B})$ whereas bu- 
A

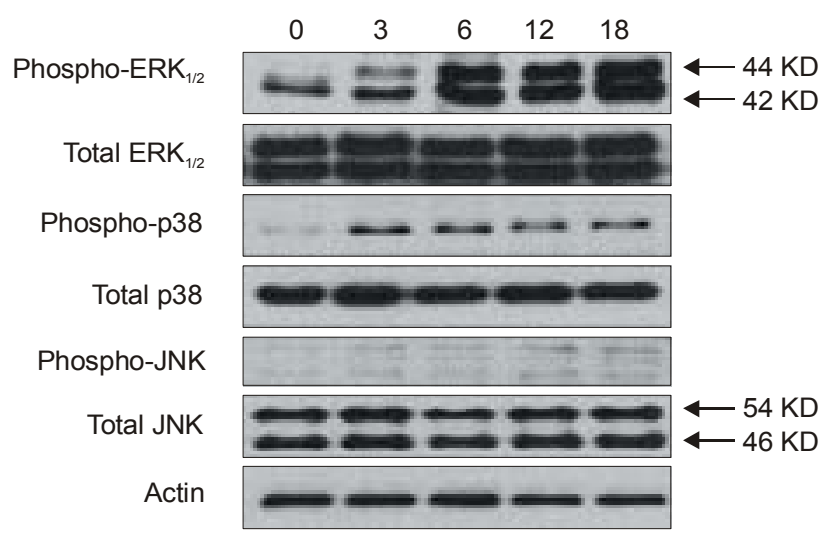

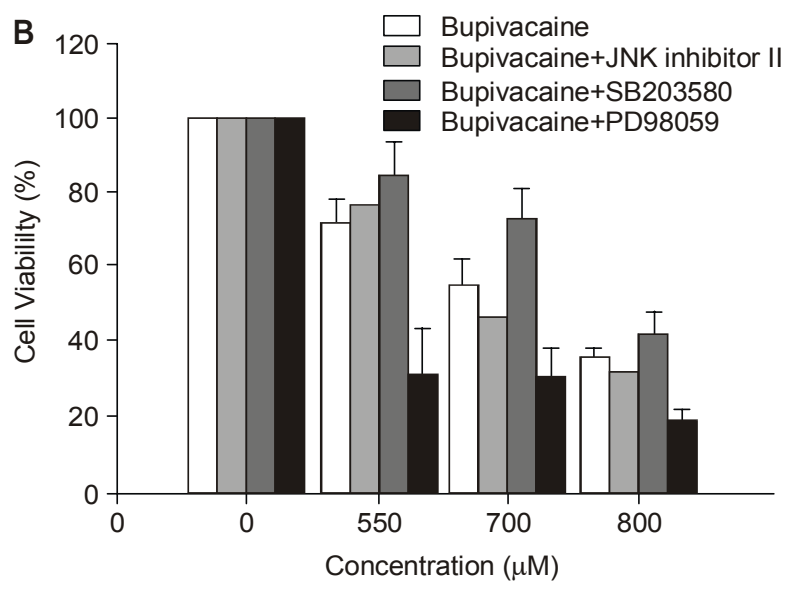

Fig. 7. Western blot analysis of MAPKs after bupivacaine treatment. (A) Cardiomyocytes were treated indicated periods of time with $700 \mu \mathrm{M}$ of bupivacaine, and Western blot analysis was done. After bupivacaine treatment in cardiomyocytes, phosphorylation of MAPKs increased. (B) ERKs and p38 MAPKs play opposite roles in bupivacaine- induced cardiomyocyte apoptosis. After preincubation with 50/mol/L PD98059 for 60 minutes or $10 / \mathrm{mol} / \mathrm{L} \mathrm{SB} 203580$ for 2 hours, cardiomyocytes were incubated with $1 / \mathrm{mol} / \mathrm{L} \mathrm{DM}$ for 24 hours. The number of TUNEL-positive cells was presented as percentage from 3 independent experiments (mean \pm SEM).

pivacaine-induced apoptosis was significantly decreased by $2 \mathrm{~h}$ pre-treatment with $10 \mu \mathrm{M} / \mathrm{L}$ SB203580, which is the p38 MAPKs inhibitor $(\mathrm{P}<0.05$, Fig. 7B). However there was no significant changes in MTT assay after cotreatment bupivacaine and JNKII, which is the JNK inhibitor.

\section{Bupivacaine induced apoptosis by $\left[\mathrm{Ca}^{2+}\right]_{i}$ not by ROS generation}

The intracellular calcium level was approximately 4 times higher after the bupivacaine treatment compared to the control (P $<0.001$, Fig. 8A). Extra-calcium chelators (EGTA) and intra-calcium chelators (BAPTA-AM) significantly inhibited the bupivacaine induced cell death $(\mathrm{P}<0.001$, Fig. 8). Because ROS have been reported to be generated from cells that are exposed to local anesthetics, we examined whether ROS are involved in bupivacaine-induced apoptosis. However, there was no change of ROS level between before and after bupivacaine treatment.

\section{Bupivacaine-induced activation of MAPKs is dependent on $\mathrm{Ca}^{2+}$}

Because chelation of extracellular or intracellular $\mathrm{Ca}^{2+} \mathrm{de}-$ creased bupivacaine-induced apoptosis, it seemed that MAPKs and calcium in the bupivacaine-induced apoptosisis closely related. The intracellular and extracellular calcium chelators increased bupivacaine-induced ERK phosphorylation and decreased p38 phosphorylation (Fig. 8) and resulted in increased cell survival.

\section{DISCUSSION}

In this study, direct cytotoxic effects of lidocaine, ropivacaine, levobupivacaine and bupivacaine on the primary cultured cardiomyocytes were compared. Among the treated local anesthetics, only bupivacaine induced apoptosis in a dose-responsive and time dependent manner less than $1 \mathrm{mM}$.

Because the rank order potency of cytotoxicity correlates well with the in vivo potency and toxicity of local anesthetics $^{21-24)}$ and higher cardiotoxicity related to bupivacaine was expected to induce cell death more than treated other local anesthetics. Therefore, among many local anesthetics, lidocaine, ropivacaine, levobupivacaine and bupivacaine are chosen for this study. But the results in this study do not limits the clinical use of bupivacaine because the cytotoxic concentration is much more (about 200 times) higher than clincally accepted dose. But in some clinical setting, continuous infusion of bupivacaine around nerve tissue or skeletal muscles for examples, apoptosis could occur., ${ }^{9,18,19)}$

Apoptosis is a distinct form of cell death, which displays characteristic alterations in the cell morphology and cell fate. Nuclear condensation, nuclear fragmentation, and sequestration of the cell fragments have been documented in the apoptotic cardiomyocytes. ${ }^{25,26)}$ Bupivacaine-induced cell death in the cardiomyocytes in this study, showed distinct apoptotic features, e.g. the morphological changes such as cell shrinkage and 

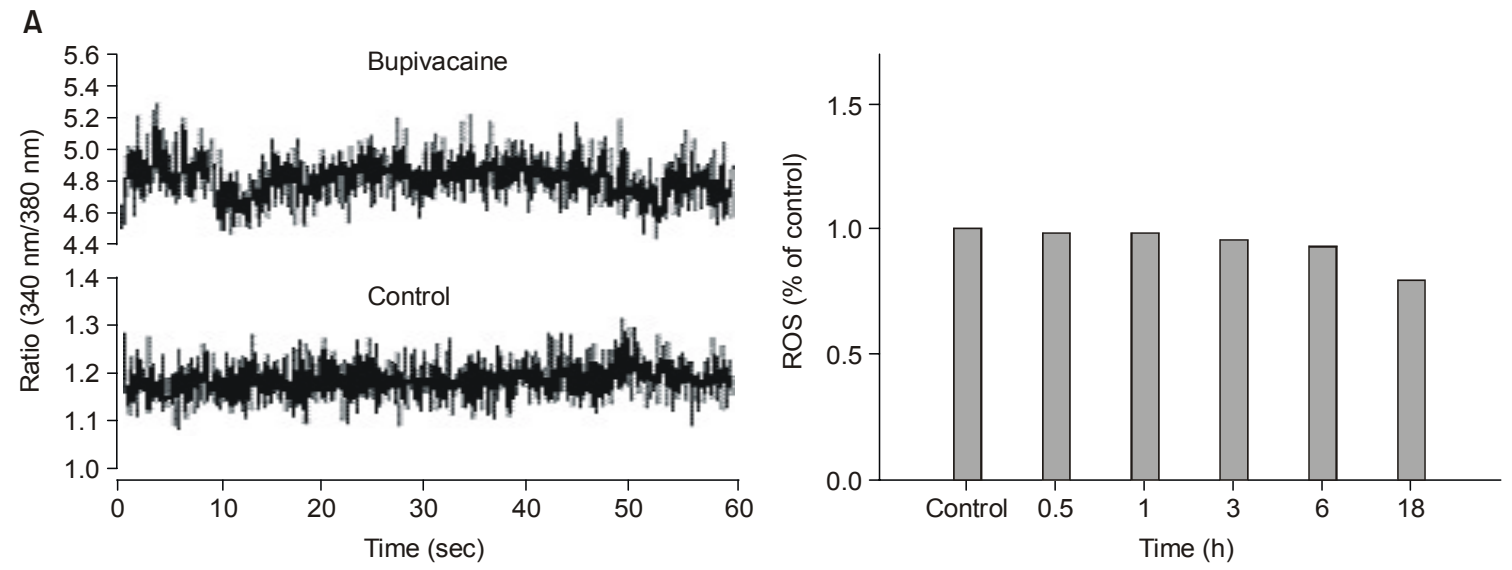

B

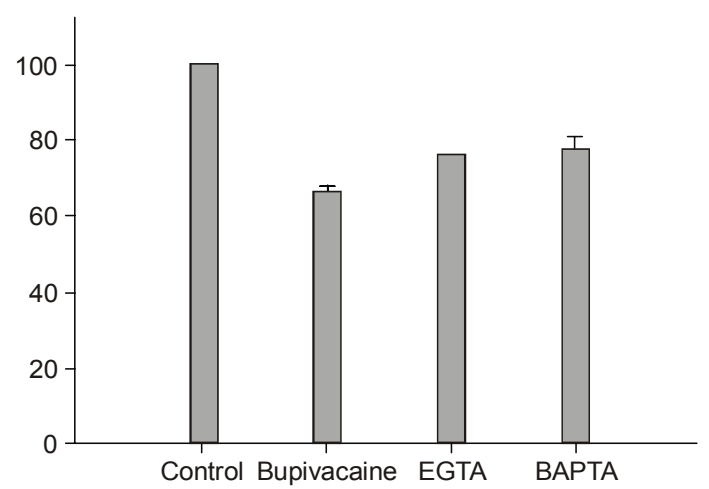

C

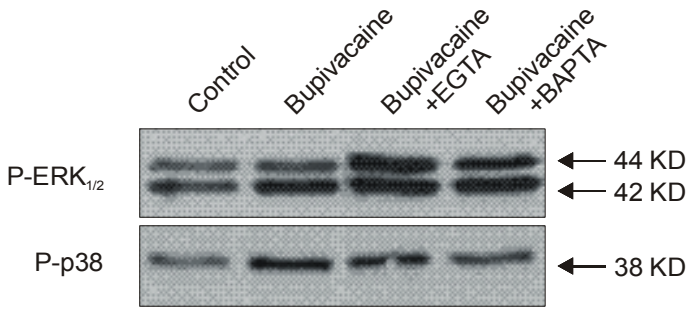

Fig. 8. Bupivacaine increase in $\left[\mathrm{Ca}^{2+}\right]_{i}$ in the cardiomyocytes $\left[\mathrm{Ca}^{2+}\right]_{i}$ was measured in the Fura-2 AM loaded cardiomyocytes in the absence (control) and the presence of 550 M bupivacaine for $18 \mathrm{hr}$. The graph represents the mean of fluorescence intensity values obtained in the ten independent cells from the three separate experiments (A). Bupivacaine-induced apoptosis was inhibited by pretreatment of intra-cellular calcium chelator (BAPTA-AM) and extra-cellular calcium chelator (EGTA) in the cardiomyocytes. The cardiomyocytes were pre- incubated with BAPTA-AM (10 $\mathrm{M})$ for $2 \mathrm{hr}(\mathrm{A})$, or EGTA $(0.5 \mathrm{mM})$ for $1 \mathrm{hr}(\mathrm{B})$ and then treated with $700 \mathrm{M}$ of bupivacaine for $18 \mathrm{hr}$. Both chelators showed significant cell death inhibition $(\mathrm{P}<0.001)$. Cell viability was determined by MTT assay. The results are represented as a mean \pm $\mathrm{SD}$ of the values obtained from three independent experiments and are expressed as a percentage of the corresponding mean control value. (C) Bupivacaine-induced activation of p38 MAPKs is dependent on $\mathrm{Ca}^{2+}$ after incubation with $5 \mathrm{mmol} / \mathrm{L}$ EGTA for 2 min and with 40/mol/L BAPTA for 30 minutes, cardiomyocytes were treated with 100 mol/L DM for 20 min. p38 MAPKs from 3 independent experiments are shown.

rounding, which are characteristic features of apoptotic death. And fluorescent DNA-binding dyes, such as Hoechst 33258 dye, are commonly used to define the nuclear chromatin morphology as a quantitative index of apoptosis within a cell culture system. ${ }^{27,28)}$ In this study, nuclear fragmentation in the Hoechst-PI staining was obvious. In addition, it was confirmed that the process of apoptosis defined based on the cellular and nuclear chromatin morphology correlated with apoptosis defined as internucleosomal DNA fragmentation assessed by gel electrophoresis. All these finding supports that bupivacaine induced cell death of cardiomyocyte is by apoptosis.

Increased intracellular calcium ${ }^{29)}$ or ROS generation ${ }^{30)}$ is com- mon finding in various apoptotic process. In this study, increased intracellular calcium was definite, but increased ROS generation was not found in bupivacaine induces apoptosis of cardiomyocyte. And addition of the intracellular and extracellular $\mathrm{Ca}^{2+}$ chelator, which affected MAPKs phosphorylation, blocked bupivacaine-induced apoptosis. Increased calcium and p38 MAPKs and intracellular signals are involved in bupivacaine-induced apoptosis.

Specifically, phosphorylation of the MAPK family, ERK and p38 were also observed in the process. But JNK activation was not definite, and inhibition of phosphorylated JNK did not affect the cell survival. So it seems that JNK family do not 
involve in bupivacaine-induced apoptosis in cultured cardiomyocyte. Inhibition of p-ERK potentiated the bupivacaine-induced apoptosis. However, inhibitors of phosphorylated p38 attenuated cardiomyocytes cell death. So p38 MAPKs is seems to be the main MAPK involved in bupivacaine-induced apoptosis in cultured cardiomyocyte.

Signal transduction via MAPKs plays a key role in a variety of cellular responses including proliferation, differentiation, and cell death. ${ }^{31)}$ More than a dozen MAPKs pathways have been identified so far. Among the MAPKs family, three members, in particular, p42/p44-MAP kinase (extracellular signal-regulated kinase, ERK), p38 MAPKs, and JNK have been well characterized. In general, activation of the ERK signal pathway usually functions to protect cells from a variety of cellular stresses. ${ }^{32,33)}$ In contrast, the JNK and p38 MAPKs signal pathways lead to cell death. ${ }^{34,35)}$ Also in our study, ERKs showed cell protective effect against bupivacaine and p38 MARKs promoted apoptosis in bupivacaine treated cardiomyocyte.

The p38 MAPKs signaling pathway activated in many cell types by cellular stressors, like UV radiation, osmotic stress, and oxidative stress. Activation of p38 MAPKs is known to results in changes in transcription, protein synthesis, cell surface receptor expression, and cytoskeletal structure, ultimately affecting cell survival or leading to the programmed cell death. Our results demonstrate that bupivacaine-induced apoptosis was related to the activation of $\mathrm{p} 38$ MAPKs signal transduction pathway in the cardiomyocytes.

Our study demonstrated bupivacaine induce apoptosis in cultured cardiomyocyte and showed increased calcicum and p38 MAPKs play key role for the first time. In promyelocytic leukemia cells HL-60, bupivacaine induced apoptosis through an indirect action of bupivacaine on mitochondria. ${ }^{7)}$ However, in this study, intracellular calcium level increased and intra and extra cellular calcium chelators inhibited bupivacaine-induced apoptosis. Zink et al. ${ }^{9)}$ and Komai et al. ${ }^{36)}$ reported that myotoxicity of bupivacaine in skeletal myocytes related to persistently higher $\left[\mathrm{Ca}^{2+}\right]_{i}$ levels. So, the intracellular calcium levels was examined in this study. These finding are consistent with our results.

In conclusion, among treated lidocaine, ropivacaine, levobupivacaine and bupivacaine, only bupivacaine induced apoptosis less than $1 \mathrm{mM}$ concentration in the primary cultured cardiomyocytes. Calcium elevation and p38 MAPKs may play important role in the bupivacaine-induced apoptosis.

\section{REFERENCES}

1. Albright GA: Cardiac arrest following regional anesthesia with etidocaine or bupivacaine. Anesthesiology 1979; 51: 285-7.

2. Kang YJ: Molecular and cellular mechanisms of cardiotoxicity. Environ Health Perspect 2001; 109(Suppl 1): 27-34.

3. Groban L: Central nervous system and cardiac effects from longacting amide local anesthetic toxicity in the intact animal model. Reg Anesth Pain Med 2003; 8: 3-11.

4. Heavner JE: Cardiac toxicity of local anesthetics in the intact isolated heart model: a review. Reg Anesth Pain Med 2002; 27: 545-55.

5. Kim M, Lee YS, Mathews HL, Wurster RD: Induction of apoptosic cell death in a neuroblastoma cell line by dibucaine. Exp Cell Res 1997; 231: 235-41.

6. Arita K, Utsumi T, Kato A, Kanno T, Kobuchi H, Inoue B, et al: Mechanism of dibucaine-induced apoptosis in promyelocytic leukemia cells (HL-60). Biochem Pharmacol 2000; 60: 905-15.

7. Unami A, Shinohara Y, Ichikawa T, Baba Y: Biochemical and microarray analyses of bupivacaine-induced apoptosis. J Toxicol Sci 2003; 28: 77-94.

8. Lee HT, Xu H, Siegel CD, Krichevsky IE: Local anesthetics induce human renal cell apoptosis. Am J Nephrol 2003; 23: 129-39.

9. Zink, W, Seif C, Bohl J: The Acute Myotoxic Effects of Bupivacaine and Ropivacaine After Continuous Peripheral Nerve Blockades. Anesth Analg 2003; 97: 1173-9.

10. Majno G, Joris I: Apoptosis, oncosis, and necrosis: an overview of cell death. Am J Pathol 1995; 146: 3-15.

11. Mallat Z, Tedgui A, Fontaliran F: Evidence of apoptosis in arrhythmogenic right ventricular dysplasia. N Engl J Med 1996; 335: 1190-6.

12. Gonzalez A, Fortuno MA, Querejeta R: Cardiomyocyte apoptosis in hypertensive cardiomyopathy. Cardiovasc Res 2003; 59: 549-62.

13. Barling B, Holtz J, Darmer D: Contribution of myocyte apoptosis to myocardial infarction. Basic Res Cardiol 1998; 93: 71-84.

14. Aoki H, Kang PM, Hampe J, Yoshimura K, Noma T, Matsuzaki $\mathrm{M}$, et al: Direct activation of mitochondrial apoptosis machinery by c-Jun N-terminal kinase in adult cardiac myocytes. J Biol Chem 2002; 277: 10244-50.

15. Sugden PH, Clerk A: Stress-responsive mitogen-activated protein kinases (c-Jun N-terminal kinases and p38 mitogen-activated protein kinases) in the myocardium. Circ Res 1998; 83, 345-52.

16. Zaugg M, Jamali NZ, Lucchinetti E, Shafiq SA, Siddiqui MA: Norepinephrine-induced apoptosis is inhibited in adult rat ventricular myocytes exposed to volatile anesthetics. Anesthesiology 2000; 93: 209-18.

17. Tan Z, Dohi S, Chen J, Banno Y, Nozawa Y: Involvement of the mitogen-activated protein kinase family in tetracaine-induced PC12 cell death. Anesthesiology 2002; 96: 1191-201.

18. Zink W, Graf BM, Sinner B, Martin E, Fink RH, Kunst G: Differential effects of bupivacaine on intracellular $\mathrm{Ca}^{2+}$ regulation: potential mechanisms of its myotoxicity. Anesthesiol 2002; 97: 
710-6.

19. Horiguchi T, Shibata MA, Ito Y, Eid NA, Abe M, Otsuki Y: Macrophage apoptosis in rat skeletal muscle treated with bupivacaine hydrochloride possible role of MCP-1. Muscle Nerve 2002; 26: 79-86.

20. Arai Y, Kondo T, Tanabe K, Zhao QL, Li FJ, Ogawa R, et al: Enhancement of hyperthermia-induced apoptosis by local anesthetics on human histiocytic lymphoma U937 cells. J Biol Chem 2002; 277: 18986-93.

21. Liu P, Feldman HS, Covino BM, Giasi R, Covino BG: Acute cardiovascular toxicity of intravenous amide local anesthetics in anesthetized ventilated dogs. Anesth Analg 1982; 61: 317-22.

22. Lee HT, Krichevsky IE, Xu H, Ota-Setlik A, D'Agati VD, Emala $\mathrm{CW}$ : Local anesthetics worsen renal function after ischemia-reperfusion injury in rats. Am J Physiol Renal Physiol 2004; 286: F111-9.

23. Santos AC, DeArmas PI: Systemic toxicity of levobupivacaine, bupivacaine, and ropivacaine during continuous intravenous infusion to nonpregnant and pregnant ewes. Anesthesiology 2001; 95: 1256-64.

24. Kim DW, Yoo HG, Choi WI, Jeon MS, Cheong MA, Lee TY: Cellular toxicity of local anesthetics by change of glucose consumption rate and lactic dehydrogenase activity in cultured media after 3 dimensional cultured cell were treated. Korean J Anesthesiol 1998; 34: 673-85.

25. Liu Y, Cigola E, Cheng W, Kajstura J, Olivetti G, Hintze TH, et al: Myocyte nuclear mitotic division and programmed myocyte cell death characterize the cardiac myopathy induced by rapid ventricular pacing in dogs. Lab Invest 1995; 73: 771-87.

26. Elsasser A, Schlepper M, Klovekorn WP, Cai WJ, Zimmermann $\mathrm{R}$, Muller KD, et al: Hibernating myocardium: an incomplete adaptation to ischemia. Circulation 1997; 96: 2920-31.

27. Ceneviva GD, Tzeng E, Hoyt DG, Yee E, Gallagher A, Engelhardt
JF, et al: Nitric oxide inhibits lipopolysaccharide-induced apoptosis in pulmonary artery endothelial cells. Am J Physiol 1998; 275: L717-28.

28. Harada-Shiba M, Kinoshita M, Kamido H, Shimokado K: Oxidized low density lipoprotein induces apoptosis in cultured human umbilical vein endothelial cells by common and unique mechanisms. J Biol Chem 1998; 273: 9681-7.

29. Kashio Y, Nakamura K, Mohammad J: Abedin, Seki M, Nishi N, et al: Galectin-9 induces apoptosis through the Calcium-CalpainCaspase-1 pathway. The J Immun 2003; 170: 3631-6.

30. Schweyer S, Soruri A, Heintze A, Radzun HJ, Fayyazu A: The role of reactive oxygen species in cisplatin-induced apoptosis in human malignant testicular germ cell lines. Internat $\mathbf{J}$ oncology 2004; 23: 1671-6.

31. Kang CD, Yoo SD, Hwang BW, Kim KW, Kim DW, Kim CM, et al. The inhibition of ERK/MAPK not the activation of JNK/ SAPK is primarily required to induce apoptosis in chronic myelogenous leukemic K562 cells. Leuk Res 2000; 24: 527-34.

32. Xia Z, Dickens M, Raingeaud J, Davis RJ, Greenberg ME: Opposing effects of ERK and JNK-p38 MAP kinases on apoptosis. Science 1995; 270: 1326-31.

33. Bogoyevitch MA: Signalling via stress-activated mitogen-activated protein kinases in the cardiovascular system. Cardiovasc Res 2000; 45: 826-42.

34. Buckley S, Driscoll B, Barsky L, Weinberg K, Anderson K, Warburton D: ERK activation protects against DNA damage and apoptosis in hyperoxic rat AEC2. Am J Physiol 1999; 277: L159-66.

35. Johnson GL, Lapadat R: Mitogen-activated protein kinase pathways mediated by ERK, JNK, and p38 protein kinases. Science 2002; 298: 1911-2.

36. Komai H, Lokuta A: Interaction of bupivacaine and tetracaine with the sarcoplasmic reticulum $\mathrm{Ca}^{2+}$ release channel of skeletal and cardiac muscles. Anesthesiology 1999; 90: 835-43. 